\title{
A SIMPLE OPERATING FRAME FOR FIELD USE
}

\author{
Lieutenant Colonel F. T. MACVICAR, F.R.C.S.(Glas. \& Edin), R.A.M.C. \\ Cambridge Military Hospital, Aldershot
}

ON joining the Field Surgical Team of 23 Parachute Field Ambulance, I found the parachute scales of equipment to have an airborne stretcher supported by two trestles to function as an operating table, and two paraffin lamps and a small Rayner lamp to supply illumination. I felt there was an urgent need to improve the operating facilities, that the equipment should be as sophisticated as possible within the limits of lightness and portability imposed by the parachute role.

I have designed a light sectional frame to support stretcher-borne casualties requiring emergency surgery. It has four tubular uprights into whose upper ends can be slotted various attachments. At the head end of the frame is a pivoted bar which allows instantaneous Trendelenburg tilt when required. P.V.C. sheeting has been utilised to make two shelves which are useful for stacking dressings, operation packs, etc.

\section{Dimensions}

Height: thirty-four and a half inches.

Length: forty-six inches.

Breadth: twenty-nine and a half inches.

Weight: (inclusive of all attachments) forty pounds.

\begin{abstract}
Attachments
Lamps

These are of very simple design. Like the other attachments they are capable of being fitted to any of the uprights of the frame. This, coupled with their three-jointed arms, allows illumination of any injured part and indeed light can be directed on to the anaesthetist's table, greatly facilitating the prepartion and drawing up into syringes of anaesthetic agents. The lamp-heads consist of the basic components of land-rover headlamps. As such they are fitted with 12-volt bulbs. Signals batteries are used as sources of power, giving an illumination period of twelve and a half hours before recharge, 240 -volt bulbs are carried for use when a generator or mains supply is available.
\end{abstract}

Mayo's table

As this can be fitted to the frame, the stand and base are no longer necessary.

\section{Drip Stand}

This can support two sets of infusion apparatus. Its height is limited to five feet nine inches for use within an airborne shelter.

\section{Lithotomy Uprights with Stirrups}

These allow good access to wounds of buttock and perineum.

\section{Arm Board}

This is useful for operating on hand or arm-or for the convenience of the anaesthetist. 


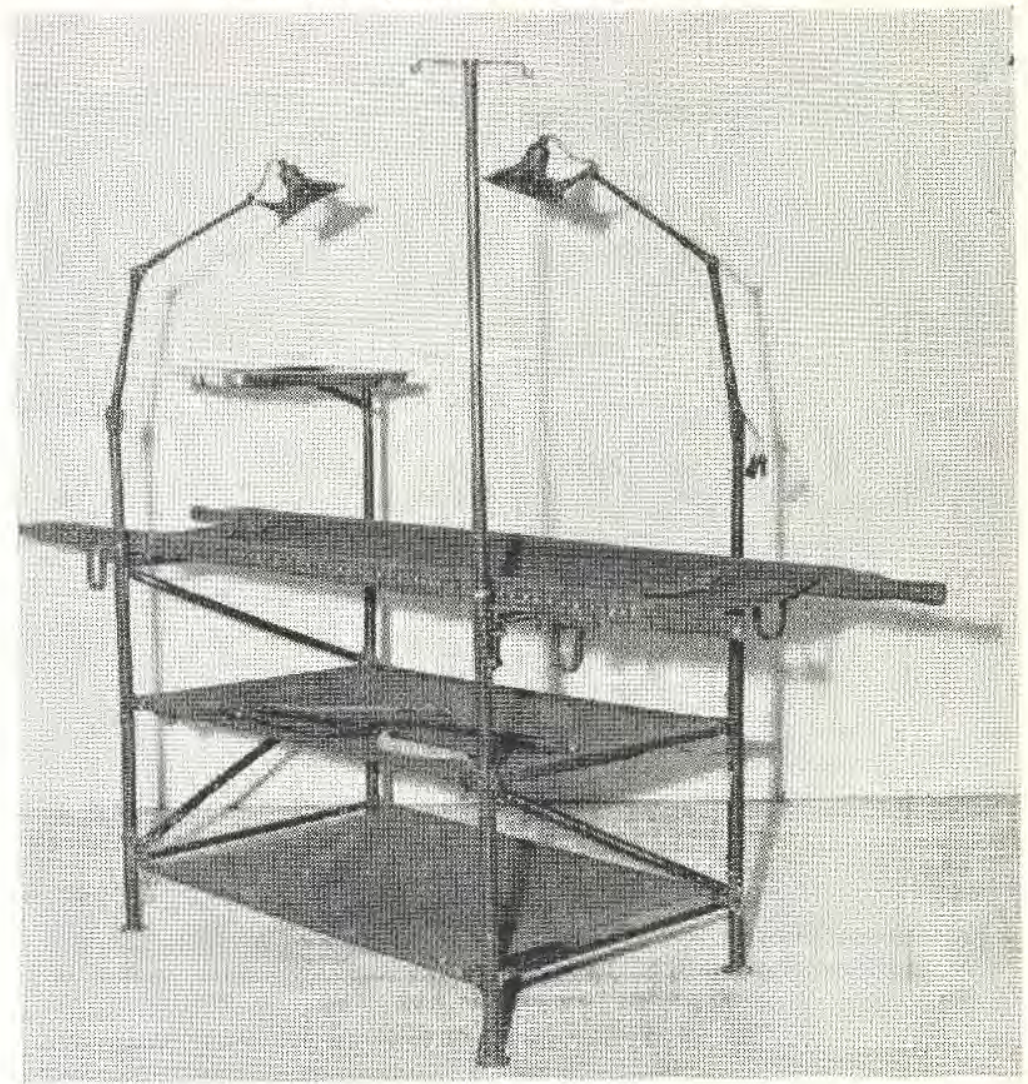

Fig. 1

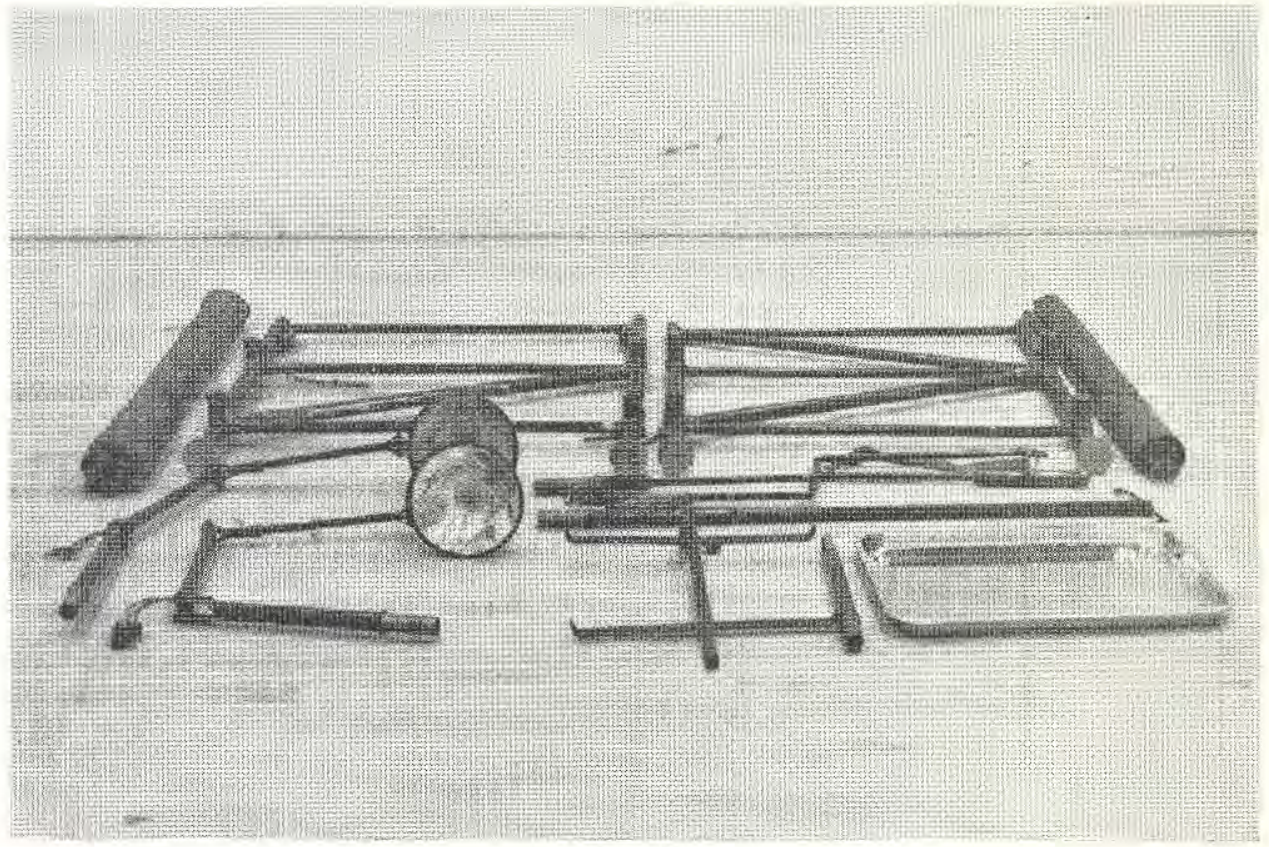

Fig. 2 


\section{Utility Clamp}

This allows any of the above items to be attached to the other parts of the frame, to the stretcher or to the frame of the airborne shelter.

\section{Discussion}

Although a stretcher is bacteriologically much less desirable than a table top, I opted for the frame because of portability, and saving in bulk and weight. Also the economy in movement of the casualty being operated upon on the stretcher on which he is brought to the A.D.S. must limit pain and shock. A table top could not have been absorbed into existing F.S.T. $\frac{1}{4}$-ton trailer load.

The frame has proved to be remarkably stable, the stability being increased by the weight of a patient. It has frequently been dropped by parachute and there has been no damage to frame, lamps or other attachments. It has been erected and dismantled on numerous occasions proving eminently "soldier proof".

The frame was built by 16 Parachute Brigade Workshops in twelve man-hours. The cost was negligible as the frame was made from unserviceable airborne shelter supports. A lighter frame could possibly be produced using light alloys, but the present one, at 40-1bs, seems adequate. I am very grateful to the Workshops for their willing help and technical skill.

\section{Summary}

The Field Surgical Team, in a parachute role, can now operate under conditions which compare favourably with a surgical team equipped on full scales. Although experience has shown that there are several refinements: which would improve any further model, this frame has filled a great gap in the equipment of 23 Parachute Field Ambulance. 